\title{
A vivência como princípio metodológico do filosofar com crianças (1)
}

\author{
Sérgio A. Sardi (2) \\ RESUMO: Ao considerarmos a conexão entre a vivência e o filosofar \\ estabelecemos um ponto de partida espontâneo, relativo a uma determinada \\ atitude, expressa na transposição a uma significação mais abrangente às nossas \\ questões, ao serem estas existencialmente assumidas. Observamos, com isso, que o \\ filosofar estabelece uma inter-relação produtiva entre o silêncio de eventos \\ interiores, relativamente idiossincráticos, aos quais denominamos vivências, $e$ as \\ exigências de clarificação, ordenação e rigor, dentre outras, no âmbito lógico- \\ lingüístico, por uma infinita aproximação entre estes dois pólos.
}

PALAVRAS-CHAVE: filosofar, vivência, linguagem, perguntar, dialogar.

Há momentos inesquecíveis em nossas infâncias. Dentre estes, há aqueles em que um relativo deslumbramento, um estranhamento, uma atitude diferenciada frente aos acontecimentos, geraram questões de outra ordem, por um modo de ver, de pensar, de sentir que rompia com o habitual (3). Talvez assim, ao rememorarmos tais experiências significativas pelas quais construímos os nexos que constituíram as nossas indagações fundamentais, as nossas visões-de-mundo, bem como os nossos estilos de pensar e de nos expressarmos, cada um possa observar a riqueza do universo interior de uma criança e, desde este percurso interior, dizer algo sobre o filosofar das crianças. Este é o ponto de partida que gostaria de propor a você.

Assim, à base de nossas próprias experiências, à base de uma determinada postura assumida desde a interioridade, desde uma certa distensão do nosso próprio ser, expressa na recuperação de nossas memórias, talvez possamos concordar que as relações entre a infância e o filosofar são muito mais espontâneas e comuns do que usualmente estamos dispostos a admitir.

Mas, deveríamos perguntar: quando, propriamente, estamos a filosofar? (4)

Consideremos uma questão: quem sou eu? Será essa uma genuína questão filosófica? Em caso afirmativo, o que a faz ser filosófica? Será a mera formulação da pergunta? Ou há uma dimensão de significação que transcende a sua formulação gramatical?

Ora, uma tal questão pode estar requerendo, desde o cotidiano, uma resposta do tipo: sou José, ou Sharon. E, mesmo que a intenção da pergunta fosse mais ampla, ela poderia ser assim compreendida. Aqui, a resposta encerra a questão, elimina-a enquanto questão, e sua ingenuidade se refere ao limite que a si mesma impõe (5). 
Poderíamos, com isso, estar formulando a mesma pergunta - quem sou eu? - e requerermos uma resposta mais ampla, assim como: sou professor de matemática, nasci em...; ou outra semelhante (6). Delimitada pela descrição de minha condição, embora mais abrangente que a mera denominação anterior, a relação entre pergunta e resposta permanece, ainda, fechada (7).

No entanto, pudemos observar, nesse breve percurso, como a mesma formulação da questão - quem sou eu? - adquiriu significações distintas em função da relação dialógica que a resposta expressava. E, embora pudéssemos estar evoluindo em um caminho, havia uma dimensão de sua significação ainda não acessada. Ao filosofar, a significação da pergunta nos remete além de sua (mera) formulação.

Mas, nesse caso, quando uma questão pode ser considerada filosófica? Qual a atitude que lhe cerca? A que tipo de diálogo conduz (8)?

Consideremos a atitude de quem se olha em um espelho, de quem contempla e reflete o fundo de seu próprio olhar; consideremos o gesto que o faz reconhecer ( $e$ desconhecer), com uma certa inquietude, a sua própria face. É possível que esse gesto, pela força de o envolver em uma relação profunda consigo mesmo, possa suscitar a questão acima prefigurada. Poderíamos, com isso, reconhecer uma potencialidade geradora relacionada a um tal evento interior, do qual a emoção é indissociável.

Nesse caso, embora tenhamos, aqui, uma formulação idêntica, ou análoga, da questão, não será outra a sua significação? Mas, o que a faz ser outra? O sentido da questão repercute, agora, na interioridade, mesmo que suscitada a partir de um diálogo com o outro, gestando um ocultamento que tensiona com a própria linguagem e é inerente à sua significabilidade.

Não me refiro a que olhar no espelho seja o ponto de partida para o estabelecimento de uma dimensão filosófica à questão que nos serviu de exemplo; mas que esse gesto indica uma atitude, desde a qual se abrem múltiplos caminhos. Ora, não seria ainda outra a significação da questão, desde que consideremos, por exemplo, a percepção do nosso próprio corpo, desde as mais variadas e profundas formas de uma tal percepção? Ou, ainda, após observarmos o olhar de outrem, ver e sentir-nos vistos por outrem, em sua presença? Ou, por outro caminho, ao considerarmos a nossa finitude, a inevitabilidade de nossa morte? Ou ao observar os nossos condicionamentos? Poderíamos, em tais contextos, repor a mesma questão com significações sempre renovadas, inclusive ao retornarmos ao mesmo evento desde o qual a geramos. Nesse movimento, que sempre de novo nos impõe novas perspectivas - cada uma inexaurivel - a questão ressurge: quem sou eu? vai assumindo significações sempre de novo repostas pelo viés da vivência originária que a significa; $e$, enquanto criativa $e$ interiormente assumida por cada um, transpassa o nosso próprio ser, nos transforma, nos demove da nossa condição, nos faz ser outros e nos lança a uma nova dinâmica de relações com a linguagem. No filosofar há um perguntar originário, cuja significação se ergue em camadas sobre a vivência que o instaura (9). 
A vivência permanece como um manancial inesgotável à reflexão; pois poderemos a ela retornar indefinidamente, por um viés sempre renovado, inclusive se isso representar uma apreensão mais profunda da mesma experiência - a qual consistirá, em última análise, em uma nova vivência, dada como evento (10) interior. Mas, não estaria implícito, nesse movimento criativo, o próprio sentido do filosofar?

As questões filosóficas não são pontuais, isoladas, mas estabelecem redes, conectam-se a outras questões, tecendo um campo mais amplo de investigação. São tais conexões que possibilitam e ampliam a complexidade e a abrangência da investigação. Assim, ampliamos, criticamente, as exigências de ordenação, coerência, amplitude, dentre outras, das relações entre pergunta e resposta (11). No entanto, antes de sermos conduzidos por uma tal via de investigação, interessanos considerar, mais amplamente, o gesto primordial, a atitude que se pôs no princípio: a vivência. A vivência, por si só, já é filosofar?

Ao considerarmos a íntima conexão entre a vivência e o filosofar estabelecemos um ponto de partida, relativo a uma determinada atitude, expressa na transposição a uma significabilidade mais abrangente às nossas questões, ao serem estas existencialmente assumidas. Uma tal condição do pensar, suscitada a partir de determinados acontecimentos dados em nossas histórias pessoais, situa-nos em uma relação com uma dimensão originária de nossas vidas. E o âmbito de nossas vidas é a referência primeira e última da linguagem, aquilo que simultaneamente reclama e confere sentido ao filosofar.

Observamos, com isso, que a significação filosófica de uma questão remete ao silêncio de um evento interior, relativamente idiossincrático, relativamente único em cada um. No entanto, estabelecemos pontos de contato, e podemos nos comunicar acerca do sentido, por exemplo, em que um tal questionamento nos faz dirigir o olhar à nossa própria condição humana, a vislumbrar o entorno de mistério que nos cerca, como a qualquer fenômeno, e nos informa, enquanto evento humano, sobre o movimento criativo - e autocriativo - dado no próprio ato de perguntar.

No entanto, a vivência indica apenas um momento de um processo mais amplo, visto que tais eventos tensionam com a linguagem. Ao nos situarem de um modo criativo na própria linguagem, operam uma dinâmica interior. $\mathrm{O}$ silêncio a que nos remetem transparece na linguagem que as mostra e, a um tempo, oculta.

E isso que se põe no princípio do filosofar, que perpassa o ato de filosofar, faz-se, simultaneamente, princípio metodológico de nossa prática educativa, segundo o concebemos. Nesse processo, o filosofar nasce de experiências significativas, as quais congregam vivência e linguagem (12). As vivências, no entanto, eventos que se produzem na esfera da interioridade, não podem ser reduzidas à sua acepção lógico-lingüística. Ademais, na reconstrução de sentidos a que somos conduzidos por esse caminho interagem a emoção, a imaginação, a memória, a interatividade prática com o meio, dentre outros processos cognitivos (13), a considerar a 
integridade do humano. A vivência consiste em um evento interior que estabelece um princípio metodológico, ao suscitar o sentido filosofante de nossas questões.

Nossa experiência, ao longo dos anos, nos mostra que vivências, mais que induzidas, podem ser suscitadas $(14)$ no contexto de determinadas atividades. Uma tal atividade pode ser, também, uma "experiência do pensamento". Mas a atividade, por si só, não garante que uma vivência se produza naquele que dela participa. Além disso, distintas atividades podem ser significativas para pessoas diversas. É que a vivência requer uma disposição, uma mutação do olhar, do sentir, uma reinvenção de nossas relações com o mundo, com os outros e com nós mesmos. Ademais, embora as vivências possam ser distintas para cada pessoa, há algumas que, por sua natureza, nos situam muito próximos das questões universais presentes na História da Filosofia (15). Podemos, por esse meio, entrar em diálogo crítico e criativo com essa História (16).

Desde que se compreenda o sentido de uma problematização filosófica a partir de uma vivência suscitada no contexto de uma atividade se faz possível, em um segundo momento, reconhecermos, nas vivências que espontaneamente participaram de nossas histórias pessoais, o sentido de um tal princípio do filosofar. Poderemos, com isso, compreender, pela nossa própria experiência, e com uma relativa autonomia, que o filosofar consiste em uma dimensão fundamental de nossas vidas, desde a infância. $\mathrm{E}$, desde que possamos internalizar uma tal atitude, estabelecendo novos pontos de partida a questões já anteriormente formuladas ao retornar aos eventos originantes que agora podem se apresentar sob novas perspectivas, ou exercitando a significabilidade filosófica de novas questões a partir de novas vivências, ou, ainda, nos abrindo ao compartilhamento de vivências com outrem, poderemos transitar a algo mais, a uma postura, assumida como dimensão do nosso próprio viver (17).

Transitamos, assim, a um modo de pensar reflexivo, complexo, criativo, autônomo, autocriativo, pela autogeração de vivências e pela conexão entre vivência e linguagem. Não esgotamos, aqui, obviamente, a caracterização de um tal modo de pensar, até mesmo porque, por um lado, ele deverá atuar criativamente com relação a si mesmo e, por outro, vincula-se ao desenvolvimento de inúmeras habilidades cognitivas associadas. Isso inclui, ainda, o aprendizado do prazer de descobrir e inventar a nós mesmos, de assumirmos integralmente a nossa unicidade.

Filosofar nos motiva à auto-descoderta, à autoconstrução, e à descoberta $e$ invenção gradual do sentido de nossas próprias vidas, o que nos disponibiliza a uma responsabilização. $\mathrm{E}$, desde o prazer e o enfrentamento que nos demove de nossa condição em direção ao alargamento do horizonte dos sentidos implícitos no ato de viver, poderemos resgatar o sentido da conquista da nossa liberdade, ou melhor, o sentido vivenciado da liberdade como uma conquista simultaneamente interior e no campo de nossas relações éticas. A criação continuada de vivências incide indelevelmente sobre o que somos; e o que somos, nosso modo de ser, educa pelo convívio. 
Aprender a filosofar consiste em um processo gradativo, relacionado não só ao desenvolvimento de todas as nossas habilidades cognitivas, mas a um aprendizado emocional. Relaciona-se com uma dimensão fundamental do nosso crescimento, compreendido em um sentido amplo, pois, ao refletir filosoficamente vamos ao encontro dos nossos próprios limites, condição de sua superação.

Mas, além de qualquer consideração teórica acerca do filosofar, o sentido do filosofar se faz filosofando, isto é, pela atividade que o significa.

Em termos pedagógicos, podemos partir da vivência da admiração, a qual consiste, numa primeira aproximação, como o afirmou Gerd A. Bornheim, em aprender a "ver as coisas como se fosse a primeira vez" (18). Para Platão e Aristóteles, a admiração (tháumas) se relaciona com o ato de podermos nos surpreender, espantar, estranhar com os fenômenos até então corriqueiros, ou com a própria ordenação da realidade (19). Observemos, ademais, como as crianças espontaneamente se admiram frente à realidade.

Consideramos, anteriormente, conexões entre vivência e linguagem. As palavras, todo o amplo espectro da linguagem, descolados das vivências, permanecem vazias de significação, meras fórmulas lógicas, conceitos cristalizados. Afinal, o que significa a palavra amor fora da experiência do amor? Por outro lado, a vivência, ela mesma, considerada à parte do universo lingüístico-conceitual, permanece muda, e reclama ser desvelada. É preciso, mais que aprender o sentido de uma problematização filosófica a partir de uma vivência, poder formulá-la em palavras, em expressões. Um tal sentido, aliás, só se apresenta completamente nessa conexão com a linguagem. A vivência ressignifica a linguagem, e a linguagem ressignifica a vivência.

Consideremos o momento de ligação, de conexão entre vivência e linguagem. Aqui, o trânsito pode efetivar-se à base de uma interrogação (20). O ato de perguntar consiste em um modo especial de nos situarmos na linguagem, condição necessária à construção do conhecimento. Já consideramos, anteriormente, ao tratarmos da relação entre a geração de vivências e a formulação de perguntas, que apreender o sentido de uma questão filosófica deve consistir, muito mais, na apreensão do sentido filosófico de uma questão. Mas, até que ponto sabemos perguntar, formular e reformular questões, e a relacioná-las entre si?

Julgo ser necessário aprender a perguntar em face da construção da nossa autonomia de pensamento. No entanto, desde que ingressamos no ensino fundamental, ou mesmo antes, somos geralmente ensinados a dar respostas a questões formuladas por outras pessoas. E esse é um gesto passivo, uma mera adequação a perguntas que não são nossas e, muitas vezes, sequer dizem respeito ao processo de nossas vidas (21). Por isso, talvez seja melhor dizer que deveríamos reaprender a perguntar, bem como o sentido em que as perguntas nos conduzem, ou desviam, de possíveis respostas.

Observemos, em um breve exemplo, como a necessidade, culturalmente induzida, que temos de apenas (ou principalmente) responder pode significar exatamente o 
inverso daquilo que pretendemos, isto é, a resposta, dependendo de como eu a considere, pode consistir em um bloqueio no processo de construção do conhecimento, pois não costumamos observar os seus limites: nesse momento, vejo um ventilador parado; logo em seguida eu o ligo, suas pás se movem em círculos... e já não posso ver cada uma delas, apenas o conjunto. Experimente fazer isso você mesmo(a) com qualquer objeto em movimento: a partir de uma certa velocidade a sua visão do objeto é modificada. Até aqui, uma mera constatação, uma observação.

Quando, após ligar o ventilador instalado no teto de uma sala de aula e mostrar o fenômeno acima descrito aos alunos, lhes perguntei: "por que não vemos cada uma das pás?", a resposta foi a seguinte: "ora, porque está em movimento". Essa resposta é "correta"? Ela é suficiente? Sim, é correta - no sentido em que não é falsa -, mas não é suficiente. Não basta responder, é preciso saber ir além das respostas que ora formulamos em busca de uma visão mais abrangente de uma determinada situação ou fenômeno. Assim progride a ciência, assim progridem todas as esferas do pensamento humano. Mas, como ir além da resposta anterior? formulando uma nova pergunta $(22)$, pois o ato de perguntar tensiona com o que já sabemos, em direção ao que não sabemos. Ela poderia ser, quanto ao caso citado, a seguinte: "por que, quando a hélice do ventilador está em movimento, não vemos cada uma das pás?" A partir desta nova pergunta exigimos uma resposta mais complexa, pois a ela deveremos relacionar novas informações, relativas, por exemplo, nesse caso, ao funcionamento da visão. A partir disso novas perguntas poderiam ser feitas, estabelecendo novas relações, novas perspectivas de abordagem, em direção a perguntas mais abrangentes e fundamentais. Talvez, nesse caso, elas pudessem estar relacionadas ao problema de saber o sentido pelo qual dizemos que o nosso conhecimento é verdadeiro, ou não; ou, ainda, ao problema de saber se o que dizemos acerca do objeto mencionado pode ser compreendido pelos outros, dentre inúmeras outras. Já estaríamos, com isso, ingressando em um campo de questionamentos relativo à História da Filosofia. Poderíamos, também, nos direcionar a outros campos de investigação, desde que nossas perguntas estivessem relacionadas, por exemplo, à estrutura de captação de imagens pelo olho humano; ou, ainda, se objetivássemos determinar a partir de qual velocidade deixamos de ver cada uma das pás do ventilador. Ingressaríamos, nos casos citados, no campo da ciência.

Quis, com o exemplo acima exposto, observar apenas que é a relação construtiva entre as perguntas $e$ as respostas que nos permitem avançar, pouco a pouco, em nosso conhecimento. Aprender a relacionar ordenadamente as perguntas e as respostas é já construir conhecimento. A simplicidade do exemplo se deve a que ele cumpre uma função analógica, isto é, visa a estabelecer determinadas relações em um contexto mais simples, as quais podem, então, ser transpostas a outros, mais complexos.

Observamos, do mesmo modo, uma transposição dos nossos questionamentos ao campo da Filosofia, a um modo de pensar que nos conduzia à universalidade e à complexidade, denotando, com isso, um caráter transdisciplinar à mesma, por se relacionar, direta ou indiretamente, com todo e qualquer conhecimento. Nesse 
movimento, a Filosofia e o filosofar operam criativamente com relação ao próprio pensar; pois, ao aprendermos a filosofar, ao aprendermos a ressignificar criativamente nossas questões, aprendemos a aprender, pois aprendemos a pensar sobre o nosso próprio processo de pensar, desde a vivência à linguagem, otimizando as próprias condições pelas quais processamos o conhecimento. $\mathrm{E}$ a História da Filosofia nos informa sobre o horizonte histórico-cultural a partir do qual efetivamos esse movimento.

Pois não são apenas as perguntas, em si, ou as respostas, que devem ser caracterizadas como filosóficas, mas também o modo como lidamos com elas. Pois o filosofar se caracteriza por uma disposição, uma postura frente ao nosso próprio conhecimento, assim como pelo grau de exigência que impomos ao mesmo. Nesse processo, a relação ordenada, encadeada, cuidadosa, metódica entre as perguntas $e$ as respostas permite o desenvolvimento de nossa capacidade de elaboração.

Observamos, com isso, que a dimensão individual e a dimensão coletiva da investigação se complementam e se repotencializam mutuamente.

Coletivamente, como M. Lipman, podemos conceber uma comunidade de investigação, onde elaboramos o diálogo com os outros. Mas o próprio conceito supracitado deveria incluir a observância da irredutibilidade da diferença, $e$ isso inclui uma revisão crítica do sentido do pensar correto. Ademais, considerar apenas esse momento como fundante do filosofar resulta em uma posição unilateral, pois não julgamos possível reduzir o processo de investigação à dimensão coletiva. Individualmente, nos referimos às vivências e ao diálogo interior. O diálogo pode ser coletivo ou interior, mas a vivência é sempre individual, mesmo que suscitada no contexto de uma atividade coletiva. Na relação entre esses dois momentos, o individual e o coletivo, gesta-se a produtividade, a elaboração gradativa de nossa visão-de-mundo, desde as perguntas que formulamos à ordenação que damos às nossas idéias (23). E, visto que o filosofar nos incita à elaboração, ordenamos e reordenamos continuamente as nossas idéias em uma exposição que faça sentido a nós mesmos e aos outros (24).

As condições de realização do diálogo filosófico, nas dimensões citadas, exigem uma atitude ética. O próprio sentido de diálogo é inseparável de uma tal atitude.

Nesse processo, em termos pedagógicos, uma investigação, desenvolvida dialogicamente, pode combinar linearidade e não-linearidade, isto é, desde que as digressões realizadas possam retornar, em um plano de discussão, à linha principal de argumentação. Estabelecemos, com isso, uma ampliação da rede de relações sobre a qual se constrói o problema do qual tratamos; abrimos novas perspectivas e potencializamos o pensamento criativo.

Do mesmo modo, uma postura filosofante e o diálogo filosófico requerem um aprendizado emocional. Por "aprendizado emocional" não me refiro, aqui, simplesmente, a um controle racional das emoções, embora isso possa ser muitas vezes necessário. Trata-se de algo mais: a aprender a conhecer também a partir das próprias emoções, a aprender como o emocionar-se participa da construção das 
significações, do sentido que cotidianamente estamos a conferir às nossas próprias vidas. A significação de vida, por exemplo, requer muito mais que uma definição; a radicalidade do problema reside em que somos, nós mesmos, participantes da vida, e é desde uma tal perspectiva que a assumimos como problema filosófico. Ora, a significação de vida iria nos faltar, se não pudéssemos nos emocionar com ela. A conexão entre emoção e cognição conformam um sentido ampliado de razão, para além de uma concepção exclusivamente lógica, sistemática e unitária.

Julgo que devemos aprender a filosofar para, então, podermos dialogar com a História da Filosofia. Do contrário, faremos apenas exegese dos textos filosóficos, e poderemos até adquirir uma certa erudição em História da Filosofia. É claro que isso não significa que a exegese e a erudição não sejam, em si mesmas, conhecimento; apenas indica que a Filosofia, nesse caso, não é assumida desde a postura que se situa em sua gênese, dada no filosofar. Para tanto, não nos basta acessar os resultados, as conclusões, mesmo parciais, dos diversos filósofos, expostas em seus escritos, mas, na medida do possível, e como um ato de interpretação que é, simultaneamente, reconstrução, o próprio processo que os orientou em suas reflexões, desde um ponto de partida assumido como uma genuína indagação filosófica; desde o nosso próprio filosofar.

Historicamente, a Filosofia pergunta pelo fundamento, pela totalidade, pelo princípio, pelo conhecimento, pelo sentido do humano, dentre outros problemas e derivações dos mesmos. Mas a Filosofia exigiu sempre a reinvenção ou a descoberta de perspectivas, relações, modos de vivenciar e formular os problemas com os quais vinha tratando. Desse modo, saber o que é a Filosofia, ou o filosofar, consiste, desde já, em mais um problema filosófico, pois a Filosofia continuamente reinventa a si mesma. Reinventar o sentido dos problemas filosóficos, reinventar a forma de expressar ou de interpretar esses problemas consiste, no entanto, em algo mais que apenas "assimilar" a História da Filosofia; ademais, ao filosofar dialogamos a história de modo a construir a nossa própria singularidade, a nossa individualidade.

Ao trabalhar com as crianças transitamos, em segundo plano, pela História da Filosofia. Num primeiro plano, filosofamos acerca e a partir do cotidiano (25). Aqui, o filosofar consiste em uma postura cognitiva. Mais ainda, o filosofar consiste também em uma postura ética e em uma postura existencial.

De uma perspectiva metodológica, o filosofar exige um reexame contínuo de tudo aquilo que já sabemos. Exige aprendermos a "pôr entre parênteses" o já sabido - o que muitas vezes é denominado desconstrução -, para então podermos avançar no caminho do conhecimento. Isso pode significar, em uma primeira acepção, livrarnos dos preconceitos, dos pressupostos; mas, mais propriamente, implica em adquirir uma nova postura frente ao modo dogmático como nos relacionamos com as nossas próprias concepções. Ao expressarmos o termo desconstruir não nos referimos a um esquecer, mas a uma suspensão que inaugura uma ressignificação pelo estabelecimento de novas relações. 
Mas, o que significa construir conhecimento? Vou sugerir apenas alguns elementos para que possamos iniciar uma reflexão acerca de um problema tão complexo - o qual envolve toda uma teoria acerca do conhecimento e da condição humana -, para então poder situar o filosofar nesse contexto. Vou partir de um exemplo criado pelo professor Celso Antunes (26). Consideremos a seguinte pergunta: o que você faz quando alguém quer saber onde você mora? Você irá lhe dizer algo do gênero: você conhece a rua "tal" ou o local "tal"? Desde que a pessoa que você deseja ensinar concorde com esse ponto de referência, você, então, passa a indicar a direção para a qual ela deverá se deslocar, observando todos os desvios, $e$ indicando novas referências: siga por essa rua em direção "tal", dobre à esquerda na primeira sinaleira, etc. Ao ensinar onde você mora a outra pessoa, você principia indicando um ponto de referência, um lugar já sabido, para que o sujeito possa, então, passo a passo, chegar ao destino pretendido.

Mas, e se ele achar que conhece o ponto de referência indicado quando, na verdade, tem uma falsa concepção, ou insuficiente, a seu respeito? Ele se perderá. Será necessário que ele reaprenda o próprio ponto de referência ou crie novos pontos de referência. Nesse caso, para construir será necessário, então, desconstruir. Ao construir ou desconstruir deveremos partir do de referência (seja ele verdadeiro ou falso) sem, no entanto, apenas lhe contrapor outro ponto de vista - pretensamente tido como "verdadeiro" - para um exame do seu ponto de vista através de um diálogo metodicamente conduzido. Esse processo está também presente na maiêutica socrática.

Nesse caso, ao lidarmos com crianças, faz-se necessário prestarmos muita atenção ao que elas dizem, e também a como elas o dizem. É preciso, inclusive, aprender a ler nas entrelinhas de suas falas, a problematizar um determinado contexto, de modo que essa problematização faça sentido para elas (27). A escuta caracteriza o educador.

A própria vivência consistirá em um novo ponto de referência, de onde, então, pelo diálogo, poderemos construir conhecimento, e filosofar com elas. Pois filosofar com as crianças implica em aprender a aprender com elas (28), em aprender sobre o modo como elas aprendem, a aprender a ouvi-las e a ouvir a nós mesmos, desde a distensão de nossas memórias, bem como de suas próprias vivências (29).

Em um exemplo da História da Filosofia, o método de educação de Sócrates (30) exigia, num primeiro momento, que o sujeito pudesse se livrar dos seus preconceitos, isto é, daquilo que ele julgava saber quando, em verdade, não o sabia. No segundo momento do seu método, Sócrates o auxiliava a "dar a luz" às suas idéias, em um processo onde o diálogo deveria poder indicar o caminho da verdade, a qual seria acessada, pouco a pouco, pelo próprio sujeito, em sua interioridade.

O diálogo consiste em uma construção conjunta do conhecimento. Com isso, requer o aprendizado do ouvir e, estabelecido este ponto de partida, do aprender a dar e receber razões, construindo dialógica e dialeticamente o saber. Ao dialogar, não disputamos idéias, mas, por um gesto de solidariedade investigativa, 
acompanhamos o raciocínio do nosso interlocutor, testando hipóteses, observando contradições, construindo novas formas de ver e de abordar um tema, conhecendo o nosso próprio processo de conhecer.

Por isso, dentre outras razões, o filósofo é amigo da sabedoria. E aquele que é amigo, que ama a sabedoria, sabe que esta não restringe o conhecimento à mera informação. A idéia de sabedoria (sophía) desde a Grécia Antiga requer, além da informação, além inclusive da lógica, uma postura ética.

O filosofar tece as raízes da forma como cada um de nós se relaciona com a sua existência e com o seu processo de crescimento, compreendendo esse termo em seu sentido mais amplo. Por outro lado, funda o sentido ético de nossas relações com os outros, com nós mesmos, com o meio ambiente e com o conhecimento. Uma tal construção do sentido de nossa condição humana conjuga um duplo caminho, onde um trabalho interior interage com as relações educativas que mantemos com os demais, tornando inseparáveis a auto-educação $e$ a heteroeducação. Assim, o filosofar quase se confunde com a trajetória de nossas existências. E essa caminhada, a jornada de nossas vidas, nós a fazemos simultaneamente sós e acompanhados, a um tempo em nossa interioridade e pelo diálogo que realizamos diariamente com aqueles com os quais convivemos. $\mathrm{O}$ amor ao outro e a si mesmo é também uma forma superior de sabedoria. Conjugamos a aventura de ser eu com essa outra, a de sermos também nós, na gradativa descoberta e invenção do sentido de nossa condição humana.

\section{Referências Bibliográficas:}

ANTUNES, Celso. As inteligências múltiplas e seus estímulos. Campinas/SP: Papirus, 1998.

ARISTÓTELES. Metafísica. Madrid: Gredos, 1970.

BERGSON, H. A Intuição Filosófica. Lisboa: Ed. Colibri, 1994.

BORNHEIM, Gerd A.. Introdução ao filosofar. RJ: Globo, 1969.

KOHAN, W. et alii. Filosofia para crianças. Vols. I, II, III, IV, V e VI. Petrópolis/RJ: Vozes, 1998.

LIPMAN, Mathew. A Filosofia vai à escola. SP: Summus editorial, 1990 (2. ed.). O pensar na educação. Petrópolis, RJ: Vozes, 1995.

Natasha - diálogos vygotskianos. POA: Artes Médicas, 1997.

LUSKOW, Abrão. Introdução à Filosofia - Educação para o pensar. Florianópolis: Edição do autor, 2000. 
MATURANA, H. Emociones y Lenguage en Educación y política. Santiago: Dolmen, 1997, p.11-37.

PLATÃO. O Sofista e Teeteto. In: CORNFORD, F. M. La teoria platônica del conocimiento. Barcelona/B. Aires: Paidos, 1983.

Oeuvres Complétes. Paris: Ed. Guillaume Budé, 1952.

RATHS, L. E. Ensinar a pensar. São Paulo: E.P.U., 1977.

SARDI, Sérgio A. Da Dialética do Admirar e do Perguntar. Veritas, POA, v. 42, no4, Dezembro 1997, p. 931-936.

Filosofar com Crianças. Veritas, POA, v.43, no 1, Março 1998, p. 185-192.

Para Filosofar com Crianças. Veritas, POA, v.43, no 2, Junho 1998, p. 413418. Caderno Linhas Críticas, Brasilia, UnB/Faculdade de educação, nos 5 e 6 , julho 1998, p. 31-37.

Partilhando a Admiração. In: KOHAN, W. \& LEAL, B. Filosofia para crianças em debate. Vol. IV. Petrópolis/RJ: Vozes, 1999, p. 381-401.

O que é comunicar e pensar? Aportes para uma dialética da alteridade. Chronos, Caxias do Sul, v.31, n.2, julho/dezembro 1998, p.131-142.

Diálogo e dialética em Platão. POA: Edipucrs, 1995.

Linhas inspiradoras para uma educação ambiental infantil. In: PELIZZOLI, M. A emergência do paradigma ecológico. Petrópolis/RJ: Vozes, 1999, p.157-160.

Ula - série Filosofar com Crianças. Volume I. POA: WS Editor, 2000.

(1) ESTE ARTIGO FOI ORIGINALMENTE PUBLICADO: In: FÁVERO, A. et al. Um olhar sobre o ensino de filosofia. Ijuí/RS: Ed. Unijuí, 2002, p. 113-128. In: Caderno Marista de Educação/Grupo de Trabalho em Educação da Província Marista de Porto Alegre, Porto Alegre/RS, V. 1, no 1, Dezembro 2001, p. 19-36. In: Revista do Centro de Educação da Universidade Federal de Santa Maria, Santa Maria/RS, v. 27, no 2, Julho/Dezembro 2002, p. 59-68.

(2) Sérgio A. Sardi é professor da FFCH/PUCRS e doutorando em Filosofia pela Unicamp/SP.

(3) Em SARDI, Sérgio A. Ula - brincando de pensar. Petrópolis, RJ: Vozes, 2004, relato algumas experiências neste sentido. 
(4) Considerando a complexidade, a história e a multiplicidade de perspectivas no tratamento deste problema, limitar-me-ei a apresentar a minha posição atual sobre o mesmo, deixando-o em aberto enquanto problema filosófico e sem pretender esgotá-lo enquanto tal.

(5) Mas, nesse breve diálogo poderia transparecer, a suspeita de que a pergunta quem sou eu - requer algo mais. Nesse caso, o sentido, ao incorporar o seu próprio ocultamento, nos situaria, agora, em um caminho.

(6) Novamente, a intenção e a compreensão poderiam não coincidir, mas essa possível resposta tece o círculo de uma relação dialógica determinada e estabelecemos, aqui, o seu sentido exclusivamente no âmbito de uma tal relação.

(7) A descrição de minha condição, no entanto, poderia suscitar em cada um, no decurso do diálogo, um distanciamento produtivo, uma reconstrução significativa, e isso poderia repercutir no desenvolvimento do próprio diálogo. Mas, nesse caso, já há aqui algo mais que a mera descrição.

(8) O perguntar é um gesto dialógico efetivado no âmbito da linguagem; requer um ouvinte, a dualidade. Concordo com PLATÃO (Cf. Teet.,189e-190a e Sof.,263e), no entanto, ao transpor o âmbito dessa dualidade também para a interioridade, compreendendo uma inter-relação produtiva entre diálogo interior e exterior (expresso minha posição a esse respeito em SARDI, S. Diálogo e dialética em Platão. POA: Edipucrs, 1995). No diálogo com outrem as possíveis quebras de uma tal coesão podem nos situar um fechamento do problema ou, dada uma disposição prévia ou assumida em um determinado contexto (inclusive emocional), podem nos situar em uma processo produtivo, visto que o inusitado na relação entre intenção e compreensão passa a ser, agora, assumido como momento de uma relação ética mais abrangente. $\mathrm{O}$ diálogo com o outro pode, assim, ser correlativo a uma certa sintonia interior (uma exigência recorrente nos diálogos platônicos), no sentido do estabelecimento de uma investigação conjunta que reconhece, sobretudo, o sentido do silêncio, o reconhecimento da significabilidade que se gesta em cada um dos interlocutores. Relativamente ao diálogo interior, no entanto, há uma tendência a uma maior coesão na conexão entre o sentido da pergunta e o da resposta, embora aqui o eu-ouvinte, ao se distanciar da própria atividade interior que interroga, gere um distanciamento produtivo de outra ordem. A vivência, no entanto, como a compreendemos, deve se produzir originariamente na esfera da interioridade. E o filosofar requer a contínua correlação entre vivência e linguagem, desde o perguntar, a metáfora, a expressividade criativa, o desdobramento lógico do diálogo, dentre outras.

(9) Poderíamos indicar perspectivas sempre renovadas pelas quais a mesma questão - quem sou eu? - passa a indicar uma atitude filosofante como, por exemplo, ao expressarmos interiormente a seguinte afirmação: "eu sou eu, e eu sei, eu sinto que existo...", desde que, nesse ínterim, estejamos, efetivamente, a pensar em nós mesmo, a sentir a nós mesmo, observando que a fala aponta para o silêncio de um evento interior, e o evento para o silêncio da fala. Ao dizer pensar, ou sentir, parto das significações dadas no cotidiano, transpassadas por uma 
atitude de estranhamento, de suspensão (desde o tháumas platônico-aristotélico à intuição filosófica bergsoniana, dentre outras, haveriam múltiplas expressões que poderiam denotar a relação existencialmente assumida com aquilo que aqui designamos pela relação entre significação e ocultamento). Aqui, o aparecer do significado expressa, simultaneamente, um ocultamento. Não há apenas uma nuança distinta de significação relativamente às demais formulações, mas é a própria significabilidade que se abre, pois a perspectiva desde a qual nos situamos com relação a uma tal questão já é outra. A idiossincrasia da significação, visto que ela remete à interioridade de cada um, é assumida como gesto criativo e nos indica um movimento mais abrangente relativamente à nossa condição humana; indica a diferença, em cada um, que nos faz, a todos, humanos. Digo humano, e há aqui algo mais que uma mera relação com a linguagem, embora permaneçamos na linguagem: antes de tudo eu sou humano, cada um de nós é humano. O aparecer gesta o ocultamento, e o ocultamento não apenas participa da significação da questão, mas ainda mais: o ocultamento, o saber-se em uma fronteira a ser sucessivamente ultrapassada, é decisivo quanto à sua própria significabilidade filosofante.

(10) Utilizo o termo evento interior para designar um acontecimento, a ocorrência de um fenômeno, relativamente à interioridade (ou seja, de acesso exclusivo a cada um), o qual foge não só ao (suposto) autodomínio do sujeito, mas, inclusive, à sua própria percepção. No perguntar filosofante é o próprio sentido de um tal evento que é primariamente posto em questão. Designa evento interior a um constructo complexo do qual a participa a emocionalidade, deixando em aberto o problema de saber se é possível estabelecer, nesse caso, um conceito determinado. Evito a expressão ato interior em função de que ela poderia, ao contrário, nos conduzir à perspectiva limitada de uma produtividade absolutizante, a exemplo do cogito cartesiano.

(11) Embora sejam elas, as respostas, patamares sobre os quais nos erguemos para observar ainda mais longe. Mas isso só é possível através de novas questões, só formuláveis à base de uma tal posição que reconhece os limites da própria resposta, compreendida agora como processo de desvelamento.

(12) Quanto à relação entre vivência e linguagem, devemos considerar o sentido em que a linguagem cumpre também o papel de suscitar um evento interior que nos remeta ao sentido originário de uma problematização filosófica. Ir da vivência à linguagem, e da linguagem à vivência, implica não somente em estabelecermos um movimento criativo, mas também na construção (e conseqüente desconstrução e reconstrução) de uma visão-de-mundo singular e original, mesmo se considerada em suas nuanças diferenciais. Nesse sentido, justifica-se, segundo compreendemos, a utilização de metáforas e neologismos e, por que não, da própria expressão poética como formas legítimas de expressão filosófica.

(13) Trabalho, aqui, com uma concepção ampliada de cognição.

(14) Ou seja, ninguém põe outra pessoa em vivência, não se faz ou aplica vivência (como muitas vezes ouço dizer), mas há um convite a um compartilhamento de 
experiências que, em última instância, se produzem na interioridade. E mesmo que esse convite possa envolver uma estratégia, o outro pode sempre aceitá-lo, ou não, estar disposto (ou predisposto) à ele, ou não. Ao pretendermos suscitar vivências devemos observar, previamente, um profundo respeito à posição daquele(s) com quem nos relacionamos. Por outro lado, pretender suscitar vivências em outrem parece requerer sempre que nos disponhamos, nós mesmos, a buscá-las por conta própria (embora possamos fazer isso involuntariamente), em função de uma postura assumida com relação ao filosofar e ao sentido desse gesto em nossas vidas.

(15) Devido aos limites deste texto pretendo desenvolver esse ponto em trabalho posterior, embora um tratamento prévio do mesmo já esteja indicado nas histórias de Ula.

(16) E, nesse sentido, a erudição pode estar destacada de uma atitude filosofante com relação aos textos clássicos, por exemplo.

(17) Assumir uma postura determinada, segundo o compreendemos, implica, por um lado, em uma relação com o prazer e, por outro, em um movimento autocriativo que requer, muitas vezes, um certo enfrentamento interior. Nessa situação aparentemente paradoxal o tensionamento entre diferença e repetição pode gerar, a cada passo, um rompimento com a condição anterior. Uma postura requer sucessivos atos em um processo de vida, uma nova resposta a cada situação e a cada disposição interior, e nisso reside o seu dinamismo. Mas uma postura, sobretudo, é assumida como gesto de liberdade, a qual é sucessivamente reafirmada, e nos situa em uma relação ética.

(18) Sobre este ponto, vide: SARDI, S. Da dialética do admirar e do perguntar. Veritas, POA, v.42, nº 4, dez/1997, p. 931-936.

(19) Cf. ARISTÓTELES, Metafísica, A, 2, 17-19 e PLATÃO, Teeteto, 155d.

(20) Considero que a metáfora, ou a metaforização, assim como os neologismos, têm também um papel relevante nessa conexão, e essa observação contém, implícita, uma orientação procedimental.

(21) Observo, nesse contexto, uma diferença entre ensino e educação.

(22) Poderíamos observar indefinidamente o fenômeno sem nos darmos conta de que existe algo mais a saber a seu respeito se não pudermos formular novas questões. Nesse caso, as questões se sucedem em uma progressão.

(23) Nesse sentido, além de dialogar, é também fundamental exercitar a escrita.

(24) O ordem da criação de um texto, no entanto, difere da ordem de sua exposição. 
(25) São inúmeros os casos de conexões de problemas filosóficos postos a partir de reflexões elaboradas dialogicamente, com base em vivências, a partir do cotidiano, seja com crianças ou adultos, com os problemas formulados no decorrer da História da Filosofia, e isso é significativo.

(26) ANTUNES, Celso. As inteligências múltiplas e seus estímulos. SP: Papirus, 1998, p. 99-103.

(27) Esse sentido pode ser acessado, primariamente, por atividades que suscitem vivências correlacionadas. E é possível conectar vivências sucessivas com as falas das crianças. As falas das crianças nos sugerem, a todo momento, motivos para serem vivencialmente trabalhados.

(28) Ademais, aprender a aprender com as crianças pode incluir um certo distanciamento de uma racionalidade logocêntrica e por demais "adulta".

(29) A postura de trabalho de um profissional do ensino depende, muito mais do que de uma metodologia, do seu estilo e do seu comprometimento frente ao ato educativo. Em termos metodológicos, a geração de vivências no processo requer, ao filosofar com as crianças, que o próprio educador esteja atento às falas das crianças, bem como às condições pelas quais a linguagem ou as atividades possam ser encadeadas em progressão. Há um planejamento prévio aos encontros, mas há um planejamento que é feito, dinamicamente, durante a próprio encontro. Nesse caso, necessita estar aberto às vivências das crianças para que possa também aprender com elas sobre o próprio modo como elas aprendem. Ademais, não se educa apenas pelo que já se aprendeu, mas pelo que se está aprendendo, pois se educa relativamente ao próprio ato de aprender, ao desejo de saber. Isso requer uma postura relacionada a um contínuo trabalho interior, resultado da práxis docente. Essa práxis, que indica uma relação dinâmica entre teoria e prática, é potencializada pelo registro das situações de aprendizagem dadas nos encontros com as crianças.

(30) Denominado maiêutica, como referido anteriormente. 